\title{
Renal innervation plays no role in oxygen-dependent control of erythropoietin mRNA levels
}

\author{
K.-U. ECKARDT, M. LeHIR, C. C. TAN, P. J. RATCLIFFE, B. KAISSLING, AND A. KURTZ \\ Physiologisches Institut der Universität Regensburg, DW-8400 Regensburg, Federal Republic of Germany; \\ Anatomisches Institut der Universität Zürich, CH-8057 Zurich, Switzerland; and Institute of Molecular \\ Medicine, John Radcliffe Hospital, Oxford OX1 3PT, United Kingdom
}

Eckardt, K.-U., M. LeHir, C. C. Tan, P. J. Ratcliffe, B. Kaissling, and A. Kurtz. Renal innervation plays no role in oxygen-dependent control of erythropoietin mRNA levels. Am. J. Physiol. 263 (Renal Fluid Electrolyte Physiol. 32): F925F930, 1992.- To assess the role of renal innervation in $\mathrm{O}_{2}$ dependent control of erythropoietin (EPO) formation, we have determined EPO mRNA levels in both kidneys of unilaterally denervated rats and sham-operated controls using RNase protection. To investigate whether possible effects of renal nerve input are related to the type of hypoxic stimulus and the degree of stimulation, animals were studied under basal conditions, after exposure to normobaric hypoxia $\left(8 \% \mathrm{O}_{2}, 4 \mathrm{~h}\right)$ or $\mathrm{CO}(0.1 \%$, $4 \mathrm{~h}$ ), and after acute hemorrhage (decrease in hematocrit from $40.8 \pm 0.5$ to $12.7 \pm 0.5 \%$ within $7 \mathrm{~h}$; mean $\pm \mathrm{SE}, n=6$ ). Serum EPO levels rose on average 22-, 49-, and 48-fold under the three stimuli and were unaffected by unilateral denervation. Renal EPO mRNA levels in unilaterally denervated animals, when expressed in arbitrary units revealed by comparison with an external standard, were $7.0 \pm 1.5$ vs. $6.3 \pm 2.0$ (normoxia), 432 \pm 136 vs. $451 \pm 156$ (normobaric hypoxia), $971 \pm 93$ vs. $930 \pm$ 120 (CO), and $604 \pm 170$ vs. $689 \pm 203$ (hemorrhagic anemia) in the intact vs. the denervated kidney (mean $\pm \mathrm{SE}, n=3$ ). Furthermore, there was no difference between EPO mRNA levels of either kidney of unilaterally denervated animals and levels in sham-operated controls. We conclude that renal nerve input plays no significant role in the control of the EPO gene under both basal and stimulated conditions.

renal denervation; ribonuclease protection; radioimmunoassay; histochemistry

PRODUCTION of the glycoprotein hormone erythropoietin (EPO) is inversely correlated with the oxygen content of arterial blood (19). The main sites of EPO formation are the kidneys and to a lesser extent the liver. The major control of EPO formation has been shown to operate at the level of its mRNA $(6,8,13,33)$. However, the mechanisms through which changes in oxygen availability determine EPO mRNA levels are incompletely understood.

The findings that isolated perfused kidneys respond to hypoxia with an increase in EPO mRNA levels (30) and EPO production $(29,32)$ indicate that principal components of the oxygen-sensing mechanisms which govern EPO formation are located in the kidney itself. This evidence cannot exclude, however, the existence of extrarenal factors modulating EPO formation in vivo. In fact, the observation that selective reduction of renal oxygen supply through constriction of renal arteries is only a minor stimulus for EPO formation has even led to the suggestion that extrarenal sites of oxygen sensing may play a predominant role in the control of EPO production (28).

Among possible pathways by which extrarenal signals might affect EPO formation in the kidneys, the efferent autonomous nervous system in particular has to be con- sidered. In early experiments electrical stimulation of the hypothalamus was shown to cause an increase in FPO titers in rabbits $(17,18)$ and monkeys $(25)$, which led to the hypothesis that oxygen-sensitive cells in the hypothalamus may influence EPO production through humoral and nervous mechanisms (18). Interestingly in this respect, inappropriately low EPO formation has recently been reported as cause of anemia in a patient with autonomic and sensory neuropathy $(1,2)$. More direct investigation, however, of the effects of renal innervation on EPO formation has so far been limited to studies based on the measurement of erythropoietic bioactivity in serum of animals exposed to hypoxia after bilateral renal nerve section, which have yielded conflicting results. Thus Beynon (7) reported increased EPO levels in rats exposed to $6 \mathrm{~h}$ of hypoxia $1 \mathrm{wk}$ after bilateral renal denervation, whereas Fink and Fisher (14) found a reduction in EPO levels in similarly treated rabbits but no effect of renal denervation in rabbits exposed to hypoxia for $18 \mathrm{~h}$.

In view of these inconsistencies we decided to study the effect of renal innervation on EPO formation by measuring EPO mRNA levels in kidneys of unilaterally denervated rats, which allows a direct intraindividual comparison in addition to comparison with sham-operated controls. To assess whether possible effects of renal nerve input are related to the type of hypoxic stimulus and the degree of stimulation, animals were investigated under basal conditions as well as after exposure to normobaric hypoxia or carbon monoxide and after acute hemorrhage.

\section{MATERIALS AND METHODS}

Animals. Male Wistar rats, weighing $180-250 \mathrm{~g}$, were used in this study.

Renal denervation. Animals were anesthetized with pentobarbital sodium $(45 \mathrm{mg} / \mathrm{kg})$. Left-sided renal denervation was performed according to the method of Bello-Reuss et al. (5). The abdominal wall was opened along the midline, and the left renal artery and vein were exposed by carefully retracting the adipose tissue and the peritoneum. Mechanical denervation was carried out using an operation microscope by sectioning any visible nerve fiber penetrating the renal hilum and by stripping the adventitia from the renal artery. To destroy any remaining nerve fibers the artery was subsequently painted with a solution of $10 \%$ phenol in ethanol. After $5 \mathrm{~min}$ of exposure to that solution the artery was washed with isotonic saline. In shamoperated animals, the left artery and vein were exposed as described above but mechanical denervation and treatment with the phenol solution were not carried out.

Stimulation of EPO formation. Normobaric arterial hypoxia, functional anemia caused by carbon monoxide inhalation, or hemorrhagic anemia were used to stimulate EPO formation 7-10 days after denervation and sham operation, respectively. 

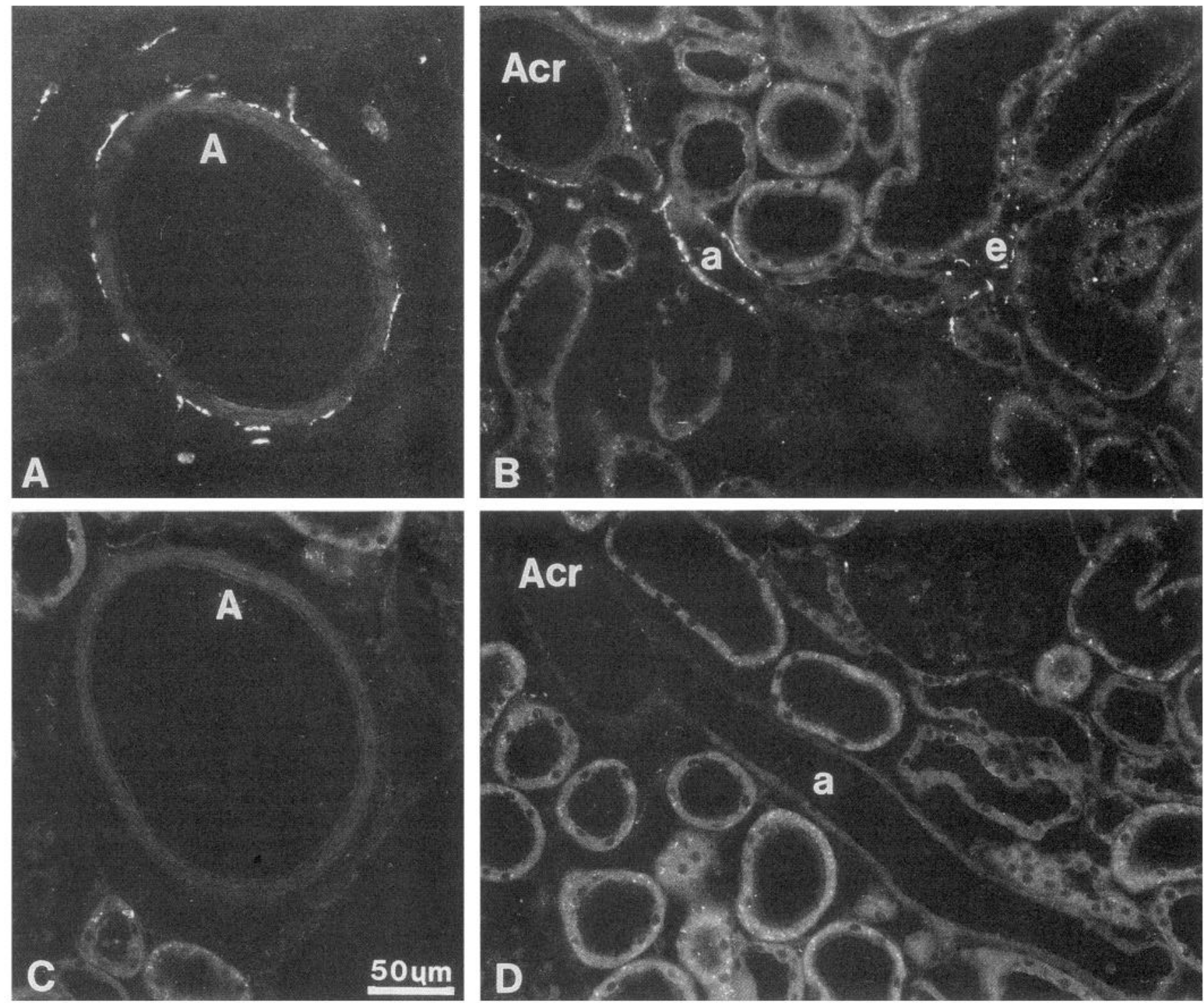

Fig. 1. Immunohistochemistry for neuropeptide $\mathrm{Y}$ on cryostat sections of renal cortex from right intact kidney $(A$ and $B$ ) and left denervated kidney $(C$ and $D$ ) of a rat. Note presence of neuropeptide $\mathrm{Y}$ in right kidney predominantly around vessels (A, arcuate artery; Acr, cortical radial artery; a, afferent; e, efferent arteriole). No staining was detectable in denervated kidney. Magnification, $\times 200$.

Littermates of the animals exposed to these stimuli were used for study of EPO formation under basal conditions.

To achieve normobaric arterial hypoxia or functional anemia, three denervated animals together with three sham-operated controls were exposed for $4 \mathrm{~h}$ to atmospheres low in oxygen $(8 \%$ $\left.\mathrm{O}_{2}\right)$ or to normal air supplemented with carbon monoxide $(0.1 \%$ $\mathrm{CO})$ in a chamber gassed with appropriate mixtures of normal air and nitrogen or normal air and carbon monoxide. Within 15 min of completion of hypoxic exposure animals were killed by cervical dislocation.

For induction of hemorrhagic anemia a catheter was inserted into the left carotid artery under brief anesthesia (methohexital sodium, $100 \mathrm{mg} / \mathrm{kg}$ ) in three denervated and three sham-operated rats. Approximately 4, 3.5, 3, and $2.5 \mathrm{ml}$ of blood were withdrawn from the catheters in hourly intervals and replaced with an equal volume of Ringer solution on the first, second, and fourth occasion and an equal volume of homologous plasma on the third occasion. Animals were killed $4 \mathrm{~h}$ after the last hemorrhage. Mean arterial blood pressure was monitored by a
Statham transducer connected to the arterial catheters before the first and fourth blood sampling and before the animals were killed.

Immediately after the animals were killed, blood was sampled from the abdominal aorta for determination of serum EPO concentrations and hematocrits (microcentrifugation) and both kidneys were rapidly removed. After determination of wet weight, one-fourth of each kidney was frozen in liquid nitrogen for histochemistry and the remaining three-fourths were homogenized in $24 \mathrm{ml}$ of guanidine thiocyanate (4 M) containing sarcosyl $(0.5 \%)$, EDTA $(10 \mathrm{mM})$, sodium citrate $(25 \mathrm{mM})$, and mercaptoethanol $(700 \mathrm{mM})$. Tissue homogenates were frozen at $-80^{\circ} \mathrm{C}$ until preparation of RNA.

Histochemistry. After coding of the kidney specimens, the completeness of denervation was ascertained in each animal using four different histochemical markers applied to $5-\mu \mathrm{m}$ thick sections cut in a cryostat. The activity of acetylcholinesterase was localized according to Karnovsky using acetylthiocholine iodide as substrate (20). Immunohistochemistry was used 
Table 1. Serum immunoreactive EPO levels in unilaterally denervated and sham-operated rats

\begin{tabular}{lcc}
\hline \hline \multirow{2}{*}{ Condition } & \multicolumn{2}{c}{ EPO, $\mathrm{mU} / \mathrm{ml}$} \\
\cline { 2 - 3 } & Sham operation & $\begin{array}{c}\text { Left-sided } \\
\text { denervation }\end{array}$ \\
\hline Normoxia & $21 \pm 0.9$ & $25 \pm 1.5$ \\
Normobaric hypoxia $\left(8 \% \mathrm{O}_{2}, 4 \mathrm{~h}\right)$ & $539 \pm 102$ & $465 \pm 94$ \\
Carbon monoxide $(0.1 \% \mathrm{CO}, 4 \mathrm{~h})$ & $1,049 \pm 186$ & $1,216 \pm 321$ \\
Hemorrhagic anemia & $1,280 \pm 461$ & $949 \pm 297$ \\
\hline
\end{tabular}

Values are means $\pm \mathrm{SE} ; n=3$. EPO, erythropoietin.

for the detection on successive sections of the neurotransmitter peptide Y (anti-neuropeptide Y rabbit polyclonal antibody; Peninsula Laboratory, Belmont, CA) as well as of the neural enzymes dopamine $\beta$-hydroxylase (anti-dopamine $\beta$-hydroxylase rabbit polyclonal antibody; Bioscience Products, Emmenbrücke, Switzerland) and choline acetyltransferase (anti-choline acetyltransferase mouse monoclonal antibody; Bioscience Products). All primary antibodies were used at the dilution 1:200; the binding sites of the primary antibodies were revealed by secondary fluorescein isothiocyanate-labeled anti-mouse immunoglobulin (Ig) G or anti-rabbit IgG antibodies from goat at a dilution of $1: 20$.

Determination of EPO mRNA. Total RNA was purified from kidney homogenates by centrifugation for $20 \mathrm{~h}$ at 33,000 rpm on a cesium chloride gradient $(5.7 \mathrm{M} \mathrm{CsCl}$ and $100 \mathrm{mM}$ EDTA). After centrifugation RNA pellets were resuspended in $300 \mu \mathrm{l}$ of $10 \mathrm{mM}$ tris(hydroxymethyl)aminomethane and $1 \mathrm{mM}$ EDTA containing $0.1 \%$ sodium dodecyl sulfate (SDS), precipitated with $3 \mathrm{M}$ sodium acetate $(0.1 \mathrm{vol})$ and ethanol ( $3 \mathrm{vol})$, and stored at $-80^{\circ} \mathrm{C}$ before analysis. EPO mRNA was measured by ribonuclease (RNase) protection as previously described (30), with the use of a rat EPO probe containing 132 base pairs of exon $\mathrm{V}$ and $\sim 300$ base pairs of the adjoining intron inserted into pSP 64 for generation of RNA transcripts. Transcripts were continuously labeled with $\left[\alpha-{ }^{32} \mathrm{P}\right] \mathrm{GTP}(410 \mathrm{Ci} / \mathrm{mmol}$; Amersham International, Amersham, UK). For hybridization, total RNA was dissolved in buffer [ $80 \%$ formamide, $40 \mathrm{mM}$ piperazine- $N, N^{\prime}$ bis(2-ethanesulfonic acid), $400 \mathrm{mM} \mathrm{NaCl}, 1 \mathrm{mM}$ EDTA, pH 8] and the RNA concentration was determined by measurement of optical density at $260 \mathrm{~nm}$. The concentration was adjusted to yield $50-\mu \mathrm{l}$ samples containing $75 \mu \mathrm{g}$ total RNA. Hybridization was performed overnight at $60^{\circ} \mathrm{C}$ with $0.7 \times 10^{6} \mathrm{cpm}$ radiolabeled EPO probe. RNase digestion with RNase A and T1 was carried out at $20^{\circ} \mathrm{C}$ for $30 \mathrm{~min}$ and terminated by the addition of proteinase $\mathrm{K}$ and SDS before purification of the protected fragments by phenol-chloroform extraction, ethanol precipitation, and electrophoresis on a denaturing $10 \%$ polyacrylamide gel. After autoradiography of the dried gel at $-70^{\circ} \mathrm{C}$ protected EPO mRNA bands were excised from the dried gel and counting was performed using a liquid scintillation counter (1500 TriCarb, Packard Instrument, Downers Grove, IL). The number of counts per minute obtained from each EPO mRNA sample was divided by the quantity of total RNA analyzed and expressed relative to an external standard consisting of $5 \mu \mathrm{g}$ pooled RNA extracted from the kidneys of severely anemic rats, which was run with each assay and assigned an arbitrary value of 1.0 . The total organ quantity of EPO mRNA was calculated from the amount of RNA extracted from aliquots of the homogenate.

Determination of serum EPO levels. Serum EPO concentrations were determined by radioimmunoassay as described (12), with the use of a rabbit antiserum raised against pure recombinant human EPO and iodinated recombinant human EPO (Amersham) as tracer. A rat serum pool enriched in EPO was prepared by exposing donor animals to hypoxia and was used as standard after calibration against the II International Reference Preparation by in vivo bioassay (12).

Statistics. Student's paired and unpaired $t$ test were used for comparison of groups. $P<0.05$ was considered significant.

\section{RESULTS}

Adequacy of unilateral renal denervation. In all the animals studied, adequacy of renal denervation was assessed by means of histochemistry. In intact kidneys acetylcholinesterase activity was detected in the large nerves along the arcuate and cortical radiate arteries as well as in the renal pelvis. As shown in Fig. 1, $A$ and $B$, the presence of neuropeptide $Y$ was revealed additionally in thinner nerve fibers throughout the kidney. Besides the large arteries, their most prominent localization was along the glomerular afferent arterioles. A similar distribution was observed for dopamine $\beta$-hydroxylase and choline acetyltransferase. In denervated kidneys all four nerve markers were undetectable except for occasional weak reaction for acetylcholinesterase in the renal pelvis. Figure 1, $C$ and $D$, illustrates an example, showing no staining with antineuropeptide $\mathrm{Y}$ antibodies in a denervated kidney.

Measurements of hematocrit, blood pressure, and serum EPO concentration. Unilateral denervation and acute exposure to normobaric hypoxia or carbon monoxide had no effect on hematocrit values (not shown). In animals subjected to hemorrhagic anemia hematocrit values decreased from $40.8 \pm 0.5 \%$ before bleeding to $19.3 \pm 0.2 \%$ after $3 \mathrm{~h}$ and to $12.7 \pm 0.5 \%$ after $7 \mathrm{~h}$, when the animals were killed (mean $\pm \mathrm{SE}, n=6$ ). This acute anemia was accompanied by a marked reduction in mean arterial blood pressure from $124.5 \pm 4.4 \mathrm{mmHg}$ to $99.2 \pm 2.7$ after $3 \mathrm{~h}$ and to $73.2 \pm 26.4$ after $7 \mathrm{~h}$ (mean $\pm \mathrm{SE}, n=6$ ). The drop in blood pressure indicates that, as expected, the volume replacement which was mainly performed with Ringer solution, was not isovolemic and consequently a strong sympathetic stimulation can be assumed in this situation.

Serum EPO levels of sham-operated and denervated animals under basal conditions and after stimulation with normobaric hypoxia, carbon monoxide, and hemorrhagic anemia are given in Table 1 . Under the three stimuli, serum EPO concentrations increased $\sim 22-, 49-$, and

Table 2. Wet weight and total RNA content in both kidneys of unilaterally denervated and sham-operated rats

\begin{tabular}{|c|c|c|c|c|}
\hline & \multicolumn{2}{|c|}{ Sham Operation } & \multicolumn{2}{|c|}{ Left-Sided Denervation } \\
\hline & Right kidney & Left kidney & Right kidney & Left kidney \\
\hline Weight, g & $0.871 \pm 0.074$ & $0.861 \pm 0.072$ & $0.855 \pm 0.051$ & $0.858 \pm 0.054$ \\
\hline Total organ RNA, mg & $1.721 \pm 0.196$ & $1.658 \pm 0.175$ & $1.648 \pm 0.143$ & $1.644 \pm 0.155$ \\
\hline
\end{tabular}

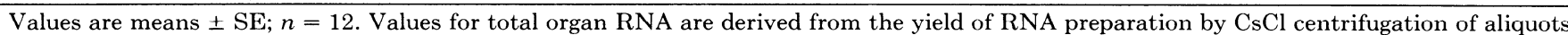
of homogenate from kidney tissue. 

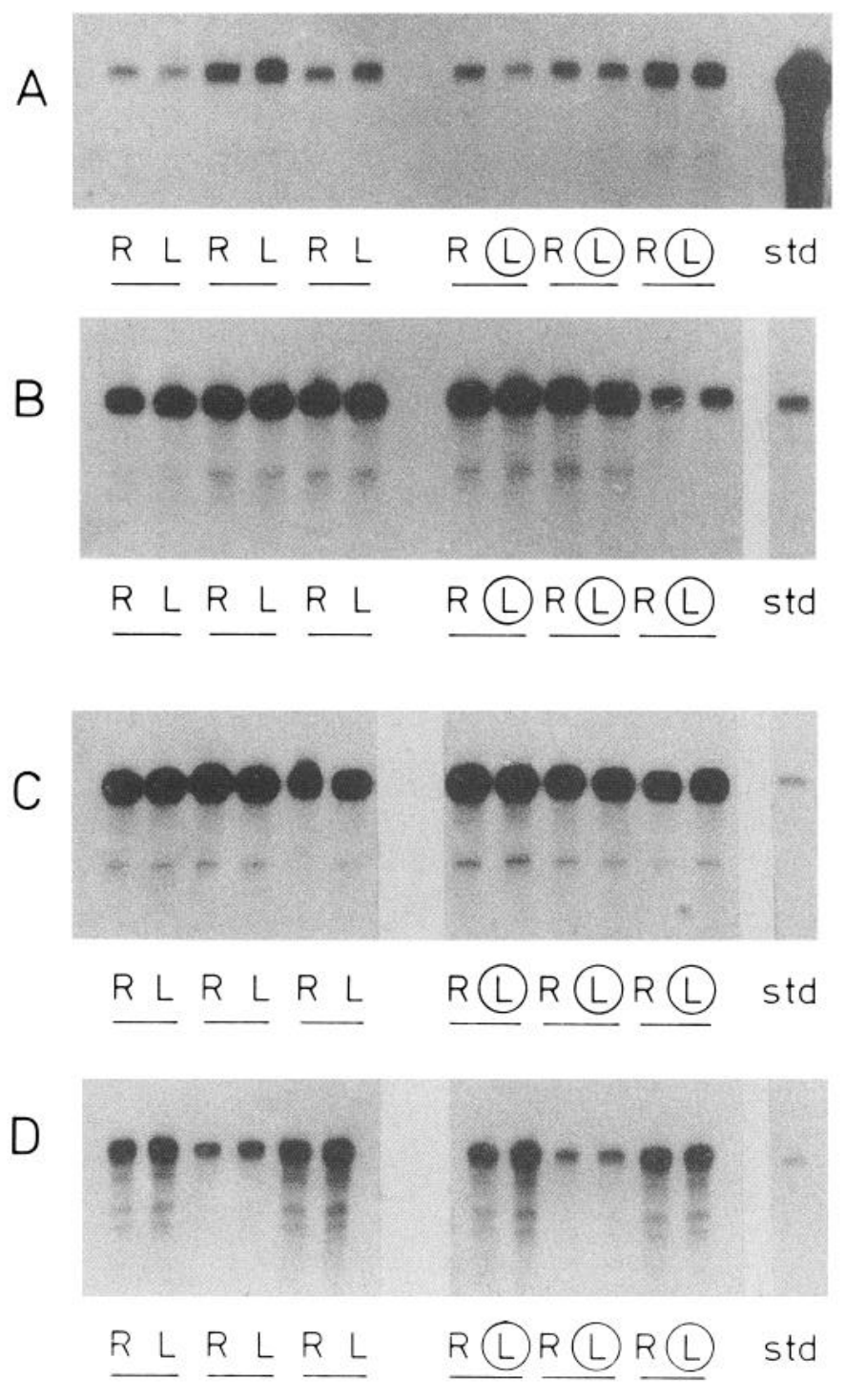

sham

unilateral

operation

denervation

Fig. 2. Autoradiographs of RNase protection assays of erythropoietin (EPO) mRNA in kidneys of denervated rats (left kidney denervated, right kidney intact) and sham-operated controls. Animals were studied under normoxic conditions $(A)$, after 4 -h exposure to normobaric hypoxia $\left(8 \% \mathrm{O}_{2} ; B\right)$, after 4 -h exposure to carbon monoxide $(0.1 \% \mathrm{CO} ; C)$, or $7 \mathrm{~h}$ after induction of hemorrhagic anemia $(D)$. Seventy-five micrograms of total RNA were analyzed on each lane. Note that 3 autoradiographs were exposed for different periods of time to reduce differences in signal intensity under 3 conditions studied. This becomes evident when signal intensities of protected fragments from a 5- $\mu \mathrm{g}$ aliquot of an external standard (Std) that was coanalyzed on each gel was compared. $\mathrm{R}$, right kidney; L, left kidney; circled L, treated left kidney.

48-fold, respectively. Under both unstimulated and stimulated conditions there was no significant difference in EPO levels between unilaterally denervated rats and sham-operated controls.

Measurements of EPO mRNA. Kidney weights and the total RNA content of the kidneys, calculated from the amount of RNA extracted from aliquots of homogenate derived from known weights of tissue, are shown in Table
2. It is apparent that renal denervation had no effect on either parameter.

To investigate the effect of renal denervation on EPO mRNA levels, $75 \mu \mathrm{g}$ of total RNA of each kidney were analyzed by RNase protection. Figure 2 shows four autoradiographs obtained with RNA from animals under basal conditions $(A)$, after 4 -h exposure to normobaric hypoxia $(B)$, after 4 -h exposure to carbon monoxide $(C)$, and after hemorrhagic anemia $(D)$. These autoradiographs were exposed for different time periods to reduce differences in signal intensity between the four different conditions. This becomes evident when considering the signal intensity from an external standard, an equal amount of which was coanalyzed on each of the three gels. The protected EPO mRNA band in each denervated kidney was of similar intensity to that from its intact fellow, suggesting that renal denervation had no appreciable effect on renal EPO mRNA production. This was confirmed by quantification of EPO mRNA levels by scintillation counting of protected EPO mRNA fragments excised from the dried polyacrylamide gels. Sample counts obtained were expressed relative to the external standard run with each assay, and the values thus obtained were used to derive estimates, in arbitrary units, of the level of EPO mRNA per microgram of total RNA in each kidney, illustrated in Fig. 3 for unstimulated and stimulated animals. Mean values of EPO mRNA levels $( \pm \mathrm{SE})$ in the intact vs. denervated kidneys were $7.0 \pm 1.5$ vs. $6.3 \pm 2.0$ under normoxic conditions, $432 \pm 136$ vs. 451 \pm 156 under normobaric hypoxia, $971 \pm 93$ vs. $930 \pm 120$ under carbon monoxide, and $604 \pm 170$ vs. $689 \pm 203$ under hemorrhagic anemia. Thus under none of the three conditions tested was the abundance of EPO mRNA in the denervated kidney significantly different from that in the contralateral kidney. Furthermore, these values were not significantly different from those in kidneys of shamoperated controls $(6.4 \pm 0.9$ under normoxia, $539 \pm 36$
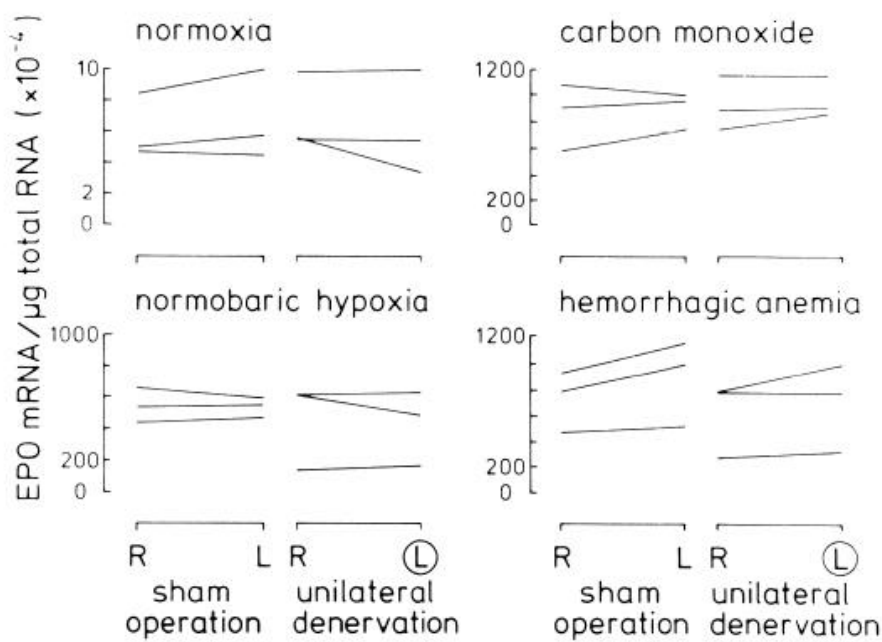

Fig. 3. Quantitative analysis of the data shown in Fig. 2. For quantitation protected EPO mRNA fragments were excised from gel and their radioactivity was counted. After subtraction of background counts, these values were related to amount of RNA analyzed $(75 \mu \mathrm{g})$ and radioactivity was measured in protected fragment from corresponding external standard. Values thus obtained represent abundance of EPO $\mathrm{mRNA} / \mu \mathrm{g}$ total RNA in arbitrary units. 
under normobaric hypoxia, $879 \pm 76$ under carbon monoxide, and $792 \pm 112$ under hemorrhagic anemia; mean \pm $\mathrm{SE}, n=6)$. Because the total RNA content of each denervated kidney was not significantly different from its intact fellow (Table 2), this also indicates that the total amount of EPO mRNA in each kidney was not affected by denervation.

\section{DISCUSSION}

The kidney, relative to its size, is known to have a richer innervation than almost any other organ $(4,16)$. Renal nerves are both afferent and efferent fibers, but most fibers are efferent, and they accompany intrarenal blood vessels $(4,16)$. Numerous neurotransmitters have been detected in the kidneys, including, for example, norepinephrine, dopamine $(4,16)$, neuropeptide Y $(31)$, and calcitonin gene-related peptide (23). The distribution of renal nerve fibers in the cortical labyrinth along intrarenal arteries and in particular afferent arterioles was also seen in this study in intact kidneys by use of immunohistochemistry for neuropeptide Y (Fig. 1) and the neural enzymes dopamine $\beta$-hydroxylase or choline acetyltransferase, whereas acetylcholinesterase was mainly apparent along arcuate and cortical radiate arteries. Others have provided additional evidence for a direct tubular innervation in the renal cortex in rat (3), monkey (27), and dog (9).

By use of in situ hybridization, EPO-producing cells have been identified in the peritubular space of the renal cortex $(22,24)$ and in particular in the cortical labyrinth (unpublished observations). In this location, these cells could possibly be direct targets of neurotransmitter release. Furthermore, alterations in renal nerve activity are known to affect renal blood flow as well as renal excretory function $(4,16)$ and could therefore theoretically have an indirect influence on EPO formation through changes in renal oxygen supply or consumption (11).

Our results show, however, that renal EPO mRNA levels are essentially unchanged in denervated kidneys (Figs. 2 and 3). This lack of an effect of renal denervation was observed over an $\sim 150$-fold range of renal EPO mRNA levels regardless of whether the animals were kept under normoxic or hypoxic conditions. Moreover, under hypoxic conditions, denervation had no effect on EPO mRNA levels regardless of whether the oxygen content of blood was lowered in the presence of a normal red cell mass through a reduction in oxygen saturation (normobaric hypoxia) or oxygen carrying capacity (carbon monoxide) or through a true reduction in red cell mass (hemorrhagic anemia). In fact the intraindividual variability in EPO mRNA levels in paired kidneys of both unilaterally denervated and sham-operated animals was rather low and less than the interindividual variability in renal EPO mRNA levels of animals studied under the same conditions. Denervation was performed by a standard technique combining mechanical dissection and chemical destruction of nerve fibers entering the renal hilum (5), and animals were studied 7-10 days after the operation, since functional reinnervation has been reported to occur after 2 wk (21). Furthermore, in each animal neural degeneration after denervation was confirmed by the failure to detect neuropeptide Y (Fig. 1) and three different neural enzymes, dopamine $\beta$-hydroxylase, choline acetyltransferase, and acetylcholinesterase, by means of immunohistochemistry. In view of these controls it therefore appears that renal innervation does not play a permissive or direct modulatory role in the oxygendependent control of EPO mRNA levels, even under a condition of strong sympathetic activation, as in the animals studied after severe hemorrhage. The lack of an effect of renal denervation in the latter group further suggests that neural effects on vascular tone in the presence of severe hemodynamic alterations also do not exert a significant indirect influence on FPO mRNA accumulation. Although we could not directly measure EPO release from denervated and control kidneys, the available evidence under all conditions tested so far indicates that EPO production is directly determined by changes in EPO mRNA levels $(6,8,13,33)$, which suggests that EPO production in the denervated kidney is in fact unchanged under the conditions investigated. Because we have not measured parameters of renal excretory function, any conclusion regarding the role of renal hemodynamics and tubular function for EPO formation is difficult to draw from these observations. We have previously suggested on the basis of experiments with diuretic drugs that EPO formation is related to proximal tubular function (11), and because acute renal denervation has been found to reduce proximal tubular absorption $(4,16)$, this effect per se might have lead to a reduction of EPO production. The observation that EPO mRNA levels were, however, unchanged indicates that such an inhibitory influence was either not of significant magnitude under the conditions used or counterbalanced, e.g., through hemodynamic alterations or direct effects of the lack of neurotransmitter release.

Our findings corroborate previous observations in patients after renal transplantation in whom evidence was obtained for an intact feedback regulation between EPO levels and hematocrit values as long as the graft was functioning $(10,26)$. Although in this clinical setting the contribution of the endogenous diseased kidneys and extrarenal sites to changes in serum EPO levels cannot be excluded with certainty, the present investigation clearly supports the ability of transplanted denervated kidneys to regulate EPO production appropriately.

Regarding the oxygen-sensing mechanisms that govern EPO production in the kidney and their signaling pathway, our experiments would indicate that any extrarenal influence on them, if present, would have to be humoral. The possibility remains, for example, that increased sympathetic activity affects EPO production through circulating catecholamines, as suggested previously by Fink et al. $(14,15)$.

We are indebted to Dr. M. Reinecke for helpful discussion and advice and to T. Schmidt and B. Rinne for valuable help in the preparation of cryostat sections. The expert technical assistance of U. Bollinger, Margit Müller, B. Gess, K.-H. Götz, and M. Hamann is gratefully acknowledged.

K.-U. Eckardt was in part supported by a European Molecular Biology Organization short-term fellowship.

Address for reprint requests: K.-U. Eckardt, Physiologisches Institut I, Universität Regensburg, Universitätsstr. 31, DW 8400 Regensburg, FRG. 
Received 2 March 1992; accepted in final form 23 June 1992.

\section{REFERENCES}

1. Anand, P., P. M. Cotes and P. Rudge. Anemia with inappropriately low erythropoietin in a new autonomic and sensory neuropathy attributed to nerve growth factor deficiency (Abstract). Clin. Sci. Lond. 80: 16, 1991.

2. Anand, P., and C. D. L. Reid. Correction by erythropoietin of anaemia in autonomic failure (Letter). Lancet 2: 759-760, 1991.

3. Barajas, L., and J. Mueller. The innervation of the juxtaglomerular apparatus and surrounding tubules: a quantitative analysis by serial section electron microscopy. J. Ultrastruct. Res. 43: 107132, 1973.

4. Barger, A. C., and J. A. Herd. Renal vascular anatomy and distribution of blood flow. In: Handbook of Physiology. Renal Physiology. Bethesda, MD: Am. Physiol. Soc., 1973, sect. 8, chapt. 10, p. 249-313.

5. Bello-Reuss, E., R. E. Colindres, E. Pastoriza-Munoz, R. A. Mueller, and C. W. Gottschalk. Effects of acute unilateral renal denervation in the rat. J. Clin. Invest. 56: 208-217, 1975.

6. Beru, N., J. McDonald, C. Lacombe, and E. Goldwasser. Expression of the erythropoietin gene. Mol. Cell. Biol. 6: 2571 2575, 1986.

7. Beynon, G. The influence of the autonomic nervous system in the control of erythropoietin secretion in the hypoxic rat. J. Physiol. Lond. 266: 347-360, 1977.

8. Bondurant, M. C., and M. J. Koury. Anemia induces accumulation of erythropoietin mRNA in the kidney and liver. Mol. Cell. Biol. 6: 2731-2733, 1986.

9. DiBona, G. F. Neurogenic regulation of renal tubular sodium reabsorption. Am. J. Physiol. 233 (Renal Fluid Electrolyte Physiol. 2): F73-F81, 1977.

10. Eckardt, K.-U., U. Frei, V. Kliem, C. Bauer, K. M. Koch, and A. Kurtz. Role of excretory graft function for erythropoietin formation after renal transplantation. Eur. J. Clin. Invest. 20: 564-574, 1990.

11. Eckardt, K.-U., A. Kurtz, and C. Bauer. Regulation of erythropoietin formation is related to proximal tubular function. Am. J. Physiol. 256 (Renal Fluid Electrolyte Physiol. 25): F942-F947, 1989.

12. Eckardt, K.-U., A. Kurtz, P. Hirth, P. Scigalla, L. Wieczorek, and C. Bauer. Evaluation of the stability of human erythropoietin in samples for radioimmunoassay. Klin. Wochenschr. 66: 241-245, 1988.

13. Eckardt, K.-U., P. J. Ratcliffe, C. C. Tan, C. Bauer, and A. Kurtz. Age dependent expression of the erythropoietin gene in rat liver and kidneys. J. Clin. Invest. 89: 753-760, 1992.

14. Fink, G. D., and J. W. Fisher. Erythropoictin production after renal denervation or $\beta$-adrenergic blockade. Am. J. Physiol. 230: 508-513, 1976.

15. Fink, G. D., L. G. Paulo, and J. W. Fisher. Effects of betaadrenergic blocking agents on erythropoietin production in rabbits exposed to hypoxia. J. Pharmacol. Exp. Ther. 193: 176-181, 1975.

16. Gottschalk, C. W., N. G. Moss, and R. E. Colindres. Neural control of renal function in health and disease. In: The Kidney: Physiology and Pathophysiology, edited by D. W. Seldin and G. Giebisch. New York: Raven, 1985, p. 581-611.
17. Halvorsen, S. Plasma erythropoietin levels following hypothalamic stimulation in the rabbit. Scand. J. Clin. Lab. Invest. 13: 564-575, 1961.

18. Halvorsen, $\mathbf{S}$. The central nervous system in regulation of erythropoiesis. Acta Haematol. 35: 65-79, 1966.

19. Jelkmann, W. Renal erythropoietin: properties and production. Rev. Physiol. Biochem. Pharmacol. 104: 140-215, 1986.

20. Karnovsky, M. J. The localization of cholinestaerase activity in rat cardiac muscle by electron microscopy. J. Cell Biol. 23: 217$232,1964$.

21. Kline, R. L., and P. F. Mercer. Functional reinnervation and development of supersensitivity to norepinephrine after denervation. Am. J. Physiol. 238 (Regulatory Integrative Comp. Physiol. 7): R353-R358, 1980.

22. Koury, S. T., M. C. Bondurant, and M. J. Koury. Localization of erythropoietin synthesizing cells in murine kidneys by in situ hybridization. Blood 71: 524-527, 1988.

23. Kurtz, A., R. Muff, W. Born, J. M. Lundberg, B.-I. Millberg, M. P. Gnädinger, D. E. Uehlinger, P. Weidmann, T. Hökfelt, and J. A. Fischer. Calcitonin gene-related peptide is a stimulator of renin secretion. J. Clin. Invest. 82: 538-543, 1988.

24. Lacombe, C., J.-L. Da Silva, P. Bruneval, J.-G. Fournier, F. Wendling, N. Casadevall, J.-P. Camilleri, J. Bariety, B. Varet, and P. Tambourin. Peritubular cells are the site of erythropoietin synthesis in the murine hypoxic kidney. J. Clin. Invest. 81: 620-623, 1988.

25. Mirand, E. A., J. T. Grace, G. S. Johnston, and G. P. Murphy. Effects of hypothalamic stimulation on the erythropoietic response in the rhesus monkey. Nature Lond. 204: 1163-1165, 1964.

26. Mirand, E. A., G. P. Murphy, T. B. Bennett, and J. T. Grace. Erythropoietin response to repeated hemorrhage in renal allotransplanted, nephrectomized, or intact dogs. Life Sci. 7: 689$696,1968$.

27. Mueller, J., and L. Barajas. Electron microscopic and histochemical evidence for a tubular innervation in the renal cortex of the monkey. J. Ultrastruct. Res. 41: 533-549, 1972.

28. Pagel, H., W. Jelkmann, and C. Weiss. A comparison of the effects of renal artery constriction and anemia on the production of erythropoietin. Pfluegers Arch. 413: 62-66, 1988.

29. Pagel, H., W. Jelkmann, and C. Weiss. Isolated serum-free perfused rat kidneys release immunoreactive erythropoietin in response to hypoxia. Endocrinology 128: 2633-2638, 1991.

30. Ratcliffe, P. J., R. W. Jones, R. E. Phillips, L. G. Nicholls, and J. I. Bell. Oxygen-dependent modulation of erythropoietin mRNA levels. J. Exp. Med. 172: 657-660, 1990.

31. Reinecke, M., and W. G. Forssmann. Neuropeptide (neuropeptide $\mathrm{Y}$, neurotensin, vasoactive intestinal polypeptide, substance $P$, calcitonin gene-related peptide, somatostatin) immunohistochemistry and ultrastructure of renal nerves. Histochemistry 89: 1-9, 1988.

32. Scholz, H., H. J. Schurek, K.-U. Eckardt, A. Kurtz, and C. Bauer. Oxygen dependent erythropoietin production by the isolated perfused rat kidney. Pfluegers Arch. 418: 228-233, 1991.

33. Schuster, S. J., E. V. Badiavas, P. Costa-Giomi, R. Weinmann, A. J. Erslev, and J. Caro. Stimulation of erythropoietin gene transcription during hypoxia and cobalt exposure. Blood 73: 13-16, 1989. 